\title{
Crianças e Adolescentes Violentados: Passado, Presente e Perspectivas para o Futuro
}

\author{
Abused Children and Adolescents: Past, Present, and Prospects for the \\ Future
}

\author{
Simone G. de Assis ${ }^{1}$ \\ ASSIS, S. G. Abused Children and Adolescents: Past, Present, and Prospects for the \\ Future. Cad. Saúde Públ., Rio de Janeiro, 10 (supplement 1): 126-134, 1994. \\ This study deals with violence committed against children and adolescents, based on a review of \\ the literature, in order to support an aproach to this problem by the field of public health. It \\ demonstrates that violence has been present since the beginning of history, and that children \\ have sometimes been the victims and sometimes the aggressors. The article presents Brazilian \\ data from the 1980s and 1990s, dealing with morbidity and mortality and specifying multiple \\ forms of violence. It calls attention to prevention as the focus for the future and as a present \\ reality in some countries. It also emphasizes the need for awareness-raising, reporting, and \\ rehabilitation for cases of violence.
}

Key words: Violence; Children; Adolescents; Morbidity; Mortality

\section{INTRODUÇÃO}

A violência sobre crianças e adolescentes acompanha a trajetória humana desde os mais antigos registros. Inumeráveis são as formas pelas quais se expressa, adaptando-se às especificidades culturais e às possibilidades de cada momento histórico. Os diversos tipos de violência costumam se expressar associadamente, conformando uma rede onde se interligam as várias violências oriundas do sistema social com aquelas praticadas no nível das relações interpessoais. Ademais, as vítimas podem se tornar agressoras, evidenciando a complexa e infindável trama existente.

O conhecimento que hoje se possui a respeito da violência ainda está em processo de construção, em função da complexidade do tema. Uma parcela significativa deste saber origina-se dos documentos históricos, que são a fonte primeira deste conhecimento. Alguns relatos evidenciam o quão arraigadas estão as formas de violência dirigidas para crianças no compor-

${ }^{1}$ Centro Latino-Americano de Estudos de Violência e Saúde da Fundação Oswaldo Cruz. Av. Brasil, 4.036, sala 702, Rio de Janeiro, RJ, 21040-361, Brasil. tamento humano. O assassinato de crianças e adolescentes é dos temas mais citados, abrangendo o infanticídio, termo usado para crianças pequenas mortas pelos pais, e os homicídios. A prática do infanticídio era aceita pelas sociedades antigas, sendo facultado aos pais grecoromanos aceitar ou renegar o filho recém-nascido, condenando-o à morte (Veyne, 1992). Nos momentos de escassez do povo hebreu, a alternativa de comer os filhos mais novos é mencionada: "Dá cá o teu filho para que hoje o comamos, e amanhã comeremos o meu filho. Cozemos pois, o meu filho, e o comemos" (II Reis 6: 26-29).

Com o passar dos anos, estes comportamentos começaram, paulatinamente, a suscitar sanções da sociedade, demonstrando uma crescente conscientização do direito das crianças à vida. Nos anos de 315-329 d.C. criou-se, na Itália, uma lei que propunha sujeitar as mãos dos pais para afastá-los do infanticídio (Lyman, 1982). Em 374 d.C. considera-se o infanticídio pecado capital, porém fora da alçada política. No ano de 830 d.C., uma mulher que mate um recém-nascido ou tente abortar deve ser excomungada, mas os sacerdotes podem reduzir o castigo na prática e impor penitência por um decênio. Apenas no início do século XII, a 
Inglaterra promulga a primeira lei que considera a morte de crianças por nutrizes ou professores como igual ao homicídio de adulto.

A violência dos pais e responsáveis frente à desobediência infanto-juvenil é também tema repetidamente considerado. Uma lei hebraica do período 1250-1225 a.C. instrui que, caso os filhos não dêem ouvidos às recomendações paternais, cabe aos anciãos da cidade puni-los, expondo-os para que sejam apedrejados pelos homens até à morte (Deuteronômio 21: 18-21).

Os séculos primeiros da era cristã trouxeram uma tênue modificação quanto à disciplina na educação, trazida pelos clérigos, outrora sofredores de uma rígida educação punitiva: "é preferível que em todo o momento temam os golpes, mas sem recebê-los" (Lyman, 1982: 110). Ou então: "pegar com vara de vime suave e flexível, ou puxar com força pelo cabelo. Às crianças nunca se deve castigar com pontapés, nem com punhos ou a palma da mão aberta, nem de nenhuma outra forma" (Mc Laughlin, 1982: 184).

O problema da disciplina não é a única dificuldade na vida em família. A rivalidade entre irmãos também é muitas vezes relatada. A vida do padre Damian, nascido em 1007 d.C. órfão e criado pelo irmão, diz que "comia restos, andava descalço, vestia farrapos e recebia golpes e pontapés, submetendo-se a este trato brutal durante anos" (Mc Laughlin, 1982: 126).

Violência ainda mais atroz é aquela vivenciada pelas crianças abandonadas, vítimas preferenciais de quase todas as formas de violência. Chamousett, em 1756, descreve a respeito das 12.000 crianças abandonadas de Paris (Badinter, 1985: 158): "morrem como moscas, sem nenhum lucro para o Estado. Pior ainda, representam um ônus para a nação, obrigada a mantê-las até que morram". Este autor idealiza uma utilização militar para essas crianças, já que não têm "pais, sem apoio algum além do que um sábio governo lhes proporciona, elas não têm ao que se apegar, e nada a perder. Poderia a própria morte parecer temível a esses homens a que nada parece prender à vida" (Badinter, 1985: 156).

A criança vista não apenas pela violência que sofre, mas pela que também pratica, é outro drama muito vivenciado e documentado. O tema da infração juvenil já preocupava a sociedade greco-romana. Rapazes ricos tinham o hábito de percorrer as ruas aos bandos, à noite, espancando ou maltratando os burgueses e destruindo lojas. Na primeira falta descoberta, a punição era a admoestação pelo governador; caso reincidissem, eram açoitados e soltos (Veyne, 1992).

As violências acima mencionadas representam apenas uma pequena parcela daquelas vivenciadas através dos séculos. Todavia, com o passar do tempo, estas e tantas outras violências continuam presentes na vida cotidiana das crianças de todos os países do mundo. Naqueles onde o desenvolvimento da cidadania e a conscientização dos direitos se deram mais precocemente, alguns tipos de violência foram minorados, porém não foram de forma alguma extintos.

No Brasil, país em que apenas recentemente se iniciou uma conscientização a este respeito, agregam-se às violências citadas outras tantas, características deste tempo e desta sociedade excludente e desigual.

O estudo da violência contra crianças na sociedade brasileira atual deve ser abordado por duas vertentes. A primeira, mais mensurável, se refere aos eventos fatais, denominados causas externas (ou violentas), entre as quais se incluem os homicídios, suicídios e acidentes. $\mathrm{Na}$ segunda vertente encontram-se variadas formas de violência que, embora potencialmente levem à morte, comumente não o fazem. $\mathrm{O}$ perfil da infância e da adolescência brasileiras, desafortunadamente no que se refere à violência, assemelha-se a uma teia em que, ao se puxar um fio, percebe-se sua ligação com toda a unidade.

\section{A SOCIEDADE BRASILEIRA: DÉCADAS DE 80 E 90}

A mortalidade por causas violentas entre crianças e adolescentes brasileiros vem crescendo nas últimas décadas, devido à ação dos acidentes de trânsito e aos homicídios. Yunes (1993) afirma que, para o ano de 1986, de cada 100 mortes por causas violentas, $35,9 \%$ ocorreram até a faixa dos 24 anos. No período compreendido entre 1979 e 1986, as taxas de mortalidade por essas causas cresceram $14 \%$ na faixa etária dos 10-14 anos e 46\% entre adolescentes dos 15-19 anos (Yunes \& Rajs, 1994). 
Outro estudo (Souza, 1994) demonstra este crescimento também entre crianças até 10 anos. No Brasil, de 1980 a 1989, o percentual de causas violentas cresceu $65,2 \%$ entre crianças de $0-4$ anos; $20,8 \%$ dos $5-9$ anos; $16,9 \%$ dos 10-14 anos; e 19\% nos adolescentes entre 15-19 anos. Esses dados indicam, portanto, a elevação do proporcional dos óbitos por estas causas em toda a infância e adolescência, especialmente na faixa etária mais jovem, o que, no entanto, perfazia, em 1989 , apenas $3,8 \%$ de óbitos por causas violentas no total das mortes infantis até 4 anos. Nas crianças de 5-9 anos, as mortes violentas respondem por $47 \%$ do total; $54,6 \%$ dos 10-14 anos; e a elevada percentagem de 70,8\% entre adolescentes de 15-19 anos.

O principal tipo de morte violenta até os 14 anos é causado pelos acidentes de trânsito (Souza, 1994). Yunes \& Rajs (1994) afirmam que estes acidentes (contrariamente à tendência de declínio observada nos demais países latinoamericanos) elevaram-se 16\% dos 10-14 anos, e 47\% dos 15-19 anos, no período de 1979 a 1986.

Já no que se refere à mortalidade por homicídios, esta foi francamente crescente no Brasil no período estudado, chegando a $82 \%$ dos $10-14$ anos e $136 \%$ dos 15-19 anos (Yunes \& Rajs, 1994).

Mello Jorge (1988), analisando as mortes de crianças e adolescentes no município de São Paulo em 1985, também observa a elevação dos homicídios nas últimas décadas e a importância das mortes de crianças até 1 ano. Os homicídios de recém-nascidos caracterizaram-se, sobretudo, pelo encontro de bebês nos depósitos de lixo. As crianças foram sufocadas ou estranguladas, espancadas ou esfaqueadas. Foram também encontrados casos de crianças mortas por maustratos dos pais, principalmente espancamento e esganadura. A autora aponta, entretanto, o perfil distinto dos adolescentes vítimas de homicídios, onde predominam o atraso e a evasão escolar, o trabalho infanto-juvenil e o uso de fumo, álcool e drogas. Este perfil indica a violência fundamental a que estes adolescentes estão submetidos: a da exclusão social.

No Estado do Rio de Janeiro, no ano de 1990, as mortes por causas violentas ocuparam o primeiro lugar entre as causas de óbitos infanto-juvenis (0-19 anos). A relevância da violência se expressa, primordialmente, na mortalidade de adolescentes. No ano de 1990, de todos os óbitos por causas violentas, 70,3\% ocorreram entre os jovens de 15 a 19 anos e $29,7 \%$ entre as idades de 0 a 14 anos. Essas mortes violentas ocorrem predominantemente no sexo masculino, com uma relação de cerca de seis homens para cada mulher de 0 a 19 anos (Claves, 1993).

O perfil de crianças e adolescentes assassinados, segundo a Secretaria de Estado de Polícia Civil (SEPC) do Rio de Janeiro, ratifica os dados de Mello Jorge. São, na sua maioria (cerca de 90\%) adolescentes de 12 a 17 anos, do sexo masculino - 90,4\% em 1992 e $92 \%$ em 1993 (Claves, 1993). Já o Centro de Articulação de Populações Marginalizadas - CEAP (1993) informa que, quanto às ocupações, as vítimas, na sua maioria, eram estudantes ou possuíam ocupações marginais, como avião/traficante e assaltante. Entretanto, ressalta que $60 \%$ das vítimas fatais de violência da Capital não tinham indicações de envolvimento com a criminalidade.

Estes estudos confirmam o preocupante agravamento da mortalidade por causas violentas entre crianças e adolescentes brasileiros, ainda mais quando se sabe que estes casos representam apenas o ápice de uma pirâmide em que a base - os casos não fatais - estão em sua maioria encobertos. Para efeito de esclarecimento, Mello Jorge (1979) cita uma estimativa norte-americana em que, para cada morte por acidente de trânsito, ocorreriam 200 casos nãofatais. Inúmeros são os obstáculos para identificar e quantificar os múltiplos tipos de violência que não levam à morte, mas que atingem de forma danosa a saúde infantil. Desta forma, apontar e dimensionar a morbidade por violência é um conhecimento ainda em formação.

Um levantamento sobre violências registrado pela SEPC aponta distintas formas denunciadas. Para a ano de 1992, mostra que, dos 2.577 eventos não-fatais envolvendo crianças e adolescentes do Rio de Janeiro de 0 a 17 anos, as ocorrências mais freqüientes foram as lesões corporais culposas $(49,5 \%)$, especialmente os acidentes e colisões, e as lesões corporais dolosas $(34,8 \%)$, que são as agressões dirigidas intencionalmente para a criança/adolescente. Os crimes sexuais alcançaram 11,2\%, sendo que 
$6,2 \%$ correspondem ao estupro e $5 \%$ ao atentado violento ao pudor. As tentativas de homicídio perfazem apenas 1,2\% das ocorrências (Claves, 1993).

Os casos registrados na polícia representam apenas uma pequena parcela da violência existente na sociedade. A violência doméstica, por exemplo, está pouco presente nas denúncias policiais, demonstrando a seletividade com que a população procura auxílio dos serviços de segurança.

A agressão física perpetrada sobre crianças e adolescentes é uma das práticas violentas mais comuns em nossa sociedade. O lar aparece como o local privilegiado para tal prática, embora esta também ocorra constantemente em crianças e adolescentes sob risco, como aquelas que estão ou trabalham nas ruas e as institucionalizadas. Também os abusos sexuais estão entre os mais freqüentemente praticados no ambiente familiar, e poucos casos chegam a domínio público. A atuação sobre estes dois tipos, associada ao abuso psicológico, abandono e negligência principalmente, tem tido sua importância reconhecida através dos crescentes casos denunciados a algumas instituições especializadas.

No Rio de Janeiro, a Associação Brasileira Multiprofissional de Proteção à Infância e Adolescência - Abrapia (1994) recebeu, só no ano de 1993, 1.548 casos de violência doméstica.

O próprio Instituto Brasileiro de Geografia e Estatística — IBGE (1989) reafirma a infância e a adolescência brasileiras como períodos propícios à violência, e aponta o domicílio como local frequiente para a ocorrência de agressões físicas nestas idades. Dados de 1988 mostram que cerca de 200.000 crianças e adolescentes declararam terem sofrido agressão física, de o total de 1 milhão de queixosos. Em $80 \%$ dos casos, os agressores infanto-juvenis eram parentes e conhecidos. Entre as meninas, a agressão se deu na própria residência em $35 \%$ dos casos, enquanto nos meninos, em 19\%.

Para o município de Duque de Caxias, Rio de Janeiro, Assis (1992) observou, nos anos de 1990-1991, a forte prevalência da violência na vida de 1.328 adolescentes-escolares. Alguns resultados da referida investigação apontam para o fato de $20 \%$ dos entrevistados haverem tido algum parente assassinado, reflexo das altas taxas de mortalidade existentes no município (Souza, 1992). Setenta e cinco por cento dos adolescentes referiram os irmãos como agentes da violência; $40 \%$, o pai; e cerca de $45 \%$, a mãe. A ocorrência de violência severa (usar arma ou ameaçar usá-la e esmurrar) foi referida por $40 \%$ dos adolescentes, quando os autores da agressão eram os irmãos, $8 \%$, quando era o pai; e $9 \%$ quando era a mãe. A partir desses dados, a autora estimou que 10.955 estudantes do município, em 1991, conviviam cotidianamente com a violência familiar, sendo que 2.665 a experienciavam na sua forma mais grave.

Quanto aos acidentes não-fatais, muito pouco se sabe acerca de sua real dimensão. Dados do setor saúde para o país são desconhecidos. Embora os acidentes de trânsito sejam os mais freqüentes, nas crianças menores outros acidentes são também muito comuns, como as quedas, queimaduras, ferimentos com objetos cortantes e/ou perfurantes. O maior problema que se tem ao identificar estes acidentes passa pela questão conceitual, já que a Organização Mundial da Saúde os considera como acontecimento fortuito, independente da vontade humana, provocado uma por força externa agindo rapidamente, manifestando-se por dano corporal ou mental (Santos, 1988). É portanto difícil considerar certos "acidentes" domésticos, e mesmo alguns de trânsito, como imprevistos ou inesperados, já que o próprio ambiente (responsabilidade da família, da comunidade e do Estado) em que a criança vive propicia a ocorrência destes "acidentes".

Um estudo populacional desenvolvido na Rocinha, Rio de Janeiro, com crianças menores de 5 anos, encontrou que $66 \%$ dos acidentes nesta faixa são por queda; $17 \%$ são cortes; e $10 \%$, queimaduras. Nenhuma criança acidentada morreu, evidenciando, mais uma vez, a distância entre as estatísticas de mortalidade e morbidade. Apenas $0,5 \%$ foram internadas em unidades de saúde, sendo que somente $12,1 \%$ buscaram atenção médica em outras unidades.

Como se percebe, a grande maioria dos acidentes não chega aos serviços de saúde. Bandigwala et al. (1990) efetuaram um estudo comparativo sobre acidentes em países latinoamericanos através dos casos de menores de 20 
anos de idade hospitalizados. Estes autores observaram que as quedas responderam por $40 \%$ das internações; os acidentes de trânsito, por $24 \%$; e as queimaduras, por $11 \%$.

A situação das crianças pobres no país atinge preocupação ainda mais alarmante quando são abandonadas e institucionalizadas. Estudo efetuado pelo Claves (1993), no Rio de Janeiro, mostra as condições de atendimento prestadas por três instituições direcionadas aos "menores" infratores, que, no entanto, convivem com as crianças abandonadas.

Observaram-se a falta de estrutura para reintegrar esses adolescentes ao convívio familiar; a não-capacitação profissional para o mercado de trabalho; a incompetência em reeducar esses jovens; e a dificuldade em habilitá-los para terem uma condição de vida melhor ao sairem da instituição. Também se constatou a ausência de meios para um trabalho efetivo com as famílias, comprometendo por demais as possibilidades de reinserção social, assim como a falta de acompanhamento quando da desinternação.

Uma pesquisa específica sobre o tema do abandono é a de Altoé (1990), a qual descreve o cotidiano da vida de crianças e adolescentes institucionalizados em uma determinada fundação filantrópica no Rio de Janeiro que atende a 2.000 crianças e adolescentes pobres. Detalha a carência generalizada das crianças devido "à transferência múltipla de ambiente de vida, ao rodízio de funcionários, ao atendimento impessoal e despersonalizante, à impossibilidade de construir laços afetivos significativos, hipoestimulação do desenvolvimento motor, fechamento para o mundo exterior, monotonia do cotidiano e pobreza das relações sociais" (Altoé, 1990: 266).

Alerta, ainda, para o sistema disciplinar rigoroso e punitivo, que castra qualquer expressão de liberdade e autonomia. O caráter do castigo imposto impossibilita a interiorização da disciplina de forma positiva, favorecendo o desenvolvimento de um superego rígido e punitivo. Termina por afirmar que "o sofrimento é fabricado pelo sistema institucional que, pela tentativa de resguardar, proteger e educar, torna a vida de milhares de crianças brasileiras infâncias desperdiçadas, infâncias perdidas, expropriadas das possibilidades de futuro" (Altoé, 1990: 268).
Neste estudo de Altoé (1990), apenas 10\% dos internos não tinham família. A grande maioria, portanto, eram abandonados nas instituições pela miséria a que suas famílias estão submetidas. Este quadro de pobreza é solo fértil para que violências igualmente cruéis germinem e se concretizem. Os meninos e meninas de rua, assim como a prostituição infanto-juvenil de ambos os sexos, são exemplos claros.

Saffioti (1989) cita uma estimativa do Fundo das Nações Unidas para a Infância (Unicef) que aponta para a possibilidade de $20 \%$ das meninas brasileiras entre 10-15 anos exercerem a prática da prostituição. A Fundação Centro Brasileiro para a Infância e Adolescência (FCBIA), citada por Dimenstein (1992), indica a existência de 500.000 meninas brasileiras vivendo na prostituição.

A vivência de meninos e meninas nas ruas significa conviver diariamente com a violência e a morte. Esta violência se dá das mais diferenciadas formas, se expressando pela falta de afeto e de condições saudáveis de vida, por ameaças, pela indução ao crime, por maus-tratos praticados por policiais e por outros "donos da rua", sendo explorados por fiscais de comércio, policiais, seguranças de lojas, além de estigmatizados como os "futuros bandidos" (Claves, 1993). O Centro Brasileiro da Infância e Adolescência calcula que, dentre os mais de 30 milhões de crianças e adolescentes que vivem em condições de pobreza no país, existem cerca de 7 milhões que vivem nas ruas (MNMMR, 1991).

Estas elevadas cifras de prostituição infantojuvenil e de meninos de rua, correntemente citadas, têm sido questionadas por diversos pesquisadores. Entretanto, mais importante que a estatística em si é o significado social que o fenômeno possui na sociedade contemporânea.

A exploração do trabalho infanto-juvenil também faz parte da realidade brasileira. Em 1987, a participação de crianças e adolescentes brasileiros nas atividades econômicas do país era de 51,4\% para o grupo de $15-17$ anos e de $18,3 \%$ para o de 10-14 anos (IBGE, 1989). Entretanto, autores tendem a concordar que exista uma alta subenumeração do trabalho infantil através das pesquisas tradicionais de mão-de-obra (Fausto \& Cervini, 1991). Mais grave ainda é que $72 \%$ dos trabalhadores infanto-juvenis o fazem em jornada de 40 ou mais 
horas semanais, certamente pondo em risco a frequiência à escola. $\mathrm{O}$ nível de renda familiar é fator determinante do ingresso no mercado de trabalho, já que as famílias urbanas pobres oferecem $75 \%$ do total da força de trabalho infanto-juvenil (Fausto \& Cervini, 1991). Mais uma vez se costata a violência da estrutura social, que discrimina os jovens pobres pela exclusão do sistema educacional.

As crianças e adolescentes, como seres humanos que são, relacionam-se com a violência, reproduzindo a díade vítima-agressor. Tratá-las primeiramente como vítimas é fundamental, pela fragilidade que possuem e pelo descaso que sempre lhes foi dirigido. Entretanto, uma análise mais aprofundada não pode deixar de perceber reações violentas, mesmo na criança de tenra idade. A violência entre irmãos e colegas pode ser vislumbrada com facilidade. Para se ter uma idéia da multiplicidade dos atos cometidos e socialmente discriminados, cita-se um levantamento dos registros da SEPC, que constatou 1.172 ocorrências registradas no Estado do Rio de Janeiro em 1992, praticadas por crianças e adolescentes. Dessas, 3,4\% foram fatais, correspondendo a 29 homicídios dolosos e 11 homicídios culposos (colisão, atropelamento e outros). As ocorrências não-fatais distribuíram-se da seguinte forma: 19 tentativas de homicídio (1,6\%); 466 lesões corporais dolosas $(39,8 \%)$; 75 lesões corporais culposas $(6,4 \%)$; 59 ameaças $(5 \%) ; 83$ atentados violentos ao pudor $(7,1 \%)$; 63 estupros $(5,4 \%) ; 15$ extorsões mediante seqüestro $(1,3 \%) ; 5$ extorsões $(0,4 \%)$; e 347 outras ocorrências não-especificadas (29,6\%).

Estas crianças e adolescentes envolvidas em crimes contra a pessoa perpetram uma elevada proporção de lesão corporal, contrariando a crença popular de que se tratam de grandes assassinos. Isso se expressa na baixa freqüência de eventos fatais cometidos por elas - apenas $3,4 \%$ - dos quais só $2,5 \%$ são homicídios dolosos.

Os atos infracionais cometidos por crianças e adolescentes registrados em outra fonte - a Segunda Vara da Infância e Adolescência no período de 1986 a julho de 1993, revelam que a grande maioria dos atos infracionais são os crimes contra o patrimônio, o envolvimento com entorpecentes (incluindo uso, tráfico e apreensão de tóxicos) e as contravenções (porte ilegal de armas e falta de habilitação para o trânsito) (Claves, 1993). A grande maioria dos atos infracionais cometidos por crianças e adolescentes foi contra o patrimônio. Em 1992, do total de atos, $76,3 \%$ foram desta natureza, sendo $46 \%$ furtos e $30,3 \%$ roubos.

A violência vivenciada e praticada por crianças e adolescentes brasileiros não se distingue demasadiamente daquela existente nos demais países latino-americanos e, mesmo, nos E.U.A. Nesses países, da mesma forma que no Brasil, a década de 80 trouxe o começo da sensibilização e da atuação da sociedade como um todo frente ao problema. As medidas mais voltadas para a atuação sobre os casos, bem como aquelas de reabilitação, são ainda pouco praticadas, nesses países, na maioria das formas de violência. Instala-se, então, a noção de prevenção à violência, que torna-se o tema de destaque para os estudiosos do assunto.

\section{PERSPECTIVAS PARA O FUTURO}

A perspectiva de prevenção da violência contra crianças e adolescentes é o grande desafio colocado nos anos 90 para todos os segmentos da sociedade. A participação de toda a sociedade no enfrentamento deste desafio é a mudança substancial que se apresenta. A atuação frente à violência deixa de estar nas mãos apenas dos serviços de segurança pública e justiça, para se fragmentar entre os diversos segmentos da sociedade civil e demais setores governamentais. A área da saúde tem tomado para si um dos mais importantes papéis nesta nova época.

Flitcraft (1994) referindo-se à violência doméstica, especificamente no que tange aos profissionais de saúde, recomenda como prevenção primária uma mudança na prática médica, de forma tal que estes se sensibilizem e reconheçam as possibilidades de auxílio que os profissionais de sáude podem prestar; no nível secundário de prevenção, a autora sugere rotinas de identificação de casos e estratégias de intervenção precoces; por fïm, para a prevenção terciária sugere a organização adequada dos serviços de saúde, já que o gasto é elevado e necessita ser bem distribuído desde os níveis de trabalhos comunitários até o dos serviços de emergência. 
Franco (1993) aponta uma primeira dificuldade ao lidar com a violência, que é o seu reconhecimento. Afirma que uma sociedade só esboça uma reação frente ao problema quando o identifica e quando conhece sua magnitude, sua dinâmica, o perfil das vítimas e dos agressores, e o que cada instituição e segmento da sociedade pode fazer. A sensibilização e o reconhecimento da violência em suas mais distintas formas é o passo primordial da prevenção. O autor enfatiza, ainda, a necessidade da redução das desigualdades, da criação de uma escala de valores onde a vida seja o valor supremo, e do compartilhamento da reponsabilidade de ação por cada grupo social.

Outros autores (Mercy et al., 1993) sugerem medidas específicas para cada tipo de violência, as quais, no entanto, devem propiciar mudanças do ambiente físico e social, bem como no nível do conhecimento e em atitudes individuais.

Estas mudanças, necessárias para o enfrentamento da violência, requerem medidas que se contrapõem aos interesses econômicos e políticos, como também a conceitos profundamente fincados. Os interesses mencionados contribuem para a precária qualidade das estatísticas (especialmente as de morbidade) existentes, que impossibilitam a sociedade conhecer sua própria fragilidade; a insustentável desigualdade social, geradora de inúmeras formas de violência (miséria, famílias vivendo nas ruas, prostituição e delinqüência, abandono, entre outras); o nãocontrole do tráfico de armas e drogas, fomentador das mais temíveis violências; os homicídios e as infrações juvenis; a omissão da sociedade; e o descaso criminoso com que o Estado repudia as crianças abandonadas, condenando-as a viver em "prisões", sem expectativas positivas de vida.

Outro nível de abordagem, talvez ainda mais difícil de ser modificado, é o dos comportamentos humanos. O que vem dando resultado nos países que já desenvolvem a prevenção há mais tempo é principalmente o enfoque educativo. Este foi altamente eficaz na modificação de certas atitudes, como a utilização de cintos de segurança, levando à redução de acidentes de trânsito, e o crescente número de notificações de casos de violência doméstica, a qual deixa de ser vista apenas como um problema do espaço circunscrito do lar. Contudo, ainda está muito longe de transformações mais profundas nos comportamentos humanos.

A necessidade humana de poder e o sentimento da posse, aliados à carência de amor e afeto, são campos propícios para o surgimento da violência. A este respeito, Restrepo (1993: 193) descreve: "quando a mão, arrogante, insiste em apoderar-se do outro, deixa de ser seda para tornar-se garra, fracassando o encontro e abrindo-se para a incorporação (do outro). A singularidade é devorada. A possibilidade de diálogo desaparece. A ternura é substituída pela violência”. O autor propõe, em oposição à violência, a ternura: "ser ternos com o mundo e os objetos implica inverter o manejo, desistir de agarrar, exercitar o jogo do colher e soltar, sem querer nunca apoderar-se do outro" (Restrepo, 1993: 193).

O conhecimento científico que hoje temos acumulado sobre a violência é fruto do sofrimento de homens, mulheres e crianças, relatado nos documentos históricos de mais de 3.000 anos. As elaboradas teorias científicas contemporâneas (sociais, biológicas, psicológicas, entre outras) que procuram definir as causas da violência associam-se, por nenhuma conseguir isoladamente explicar o fenômeno. A questão da interdisciplinaridade, no enfrentamento ao problema, é a aquisição recente mais importante, em conjunto com a "descoberta" da importância da participação de toda a sociedade, indiscriminadamente, para se alcançar medidas preventivas eficazes. A luta pela prevenção dos mais diversos tipos de violência, em todos os níveis, assim como pela reabilitação dos casos já ocorridos, deve ocupar posição privilegiada na enorme tarefa que se apresenta.

Por fim, devemos atentar para as lições do passado, que ainda têm muito o que nos ensinar, até que, um dia, possamos descrever uma sociedade onde não existam mais seres como Páctula, descrita por São Jerônimo no ano de 413 d.C., tão distante e tão próxima da realidade contemporânea.

"Estes são pois os tempos em que nascestes, Páctula, morte e destruição são os jogos de sua infância. Conhecerás lágrimas antes que o riso, a tristeza antes que a alegria. Apenas chegada ao mundo terá que sair dele". (Lyman, 1982: 105) 


\section{RESUMO}

ASSIS, S. G. Crianças e Adolescentes Violentados: Passado, Presente e Perspectivas para o Futuro. Cad. Saúde Públ., Rio de Janeiro, 10 (suplemento 1): 126-134, 1994.

O presente trabalho aborda o tema da violência em crianças e adolescentes, com base na revisão da literatura e de pesquisas, visando subsidiar a abordagem do problema no campo da Saúde Pública. Constata que esta violência está presente desde os mais antigos registros históricos, apontando a criança ora como vítima, ora como autora. Apresenta dados para o Brasil, nas décadas de 80 e 90 , abrangendo a morbi-mortalidade e especificando as múltiplas formas de violência. Aponta a perspectiva para o futuro, que é a da prevenção, já sendo utilizada com sucesso em alguns países. Enfatiza a necessidade da sensibilização, notificação e reabiliatação sobre a violência.

Palavras-Chave: Violência; Crianças; Adolescentes; Morbidade; Mortalidade

\section{REFERÊNCIAS BIBLIOGRÁFICAS}

ABRAPIA (Associação Brasileira Multiprofissional de Proteção à Infância e Adolescência), 1994. Fornal da ABRAPIA, Rio de Janeiro, ano III, $\mathrm{n}^{\circ}$ 11.

ALTOÉ, S., 1990. Infâncias Perdidas: O Cotidiano nos Internatos/Prisão. Rio de Janeiro: Xenon.

ASSIS, S. G., 1992. Violência, Criança e Comportamento. Um Estudo em Grupos Sociais Distintos. Relatório Final de Pesquisa, Rio de Janeiro: Claves/Fiocruz. (Mimeo.)

BANDIGWALA, S. I.; ANZOLA-PEREZ, R., ROMER, C. C.; SCHIMDT, B.; VALDEZ-LAZO, F.; TORO, J. \& D'SUZE, C., 1990. The incidence of injuries in young people: I. Methodology and results of a collaborative study in Brazil, Chile, Cuba and Venezuela. International Fournal of Epidemiology, 19: 115-124.

BADINTER, E., 1985. Um Amor Conquistado. $O$ Mito do Amor Materno. Rio de Janeiro: Nova Fronteira.

CEAP (Centro de Articulação de Populações Marginalizadas), 1993. Pesquisa Sobre Extermínio. Rio de Janeiro: Ceap. (Mimeo.)
CLAVES (Centro Latino-Americano de Estudos de Violência e Saúde), 1993. Estudo Multidisciplinar Sobre as Atuais Condições de Atendimento a Crianças e Adolescentes do Rio de Janeiro em Situações Especialmente Difíceis. Municípios de Rio de Janeiro e Duque de Caxias. Relatório Final de Pesquisa, Rio de Janeiro: Claves/Fiocruz. (Mimeo.)

DIMENSTEIN, G., 1992. Meninas da noite. $A$

Prostituição de Meninas Escravas no Brasil. São Paulo: Ática.

FAUSTO, A. \& CERVINI, R., 1991. O Trabalho e a Rua: Crianças e Adolescentes no Brasil

Urbano dos Anos 80. São Paulo: Cortez.

FRANCO, A. S., 1993. La Violencia, Una Realidad Social. Violencia Intrafamiliar. Medellín: Litoarte.

FLITCRAFT, A., 1993. Physicians and domestic violence: challenges for prevention. Health Affairs, 12: 154-160.

IBGE (Fundação Instituto Brasileiro de Geografia e Estatística), 1989. Crianças e Adolescentes: Indicadores Sociais. Rio de Janeiro: IBGE.

LYMAN, R. B., 1982. Barbarie y religion: la infancia a fins de la epoca romana y comienzos de la edad media. In: Historia de la Infancia (L. De Mause, org.), pp. 93-120, Madrid: Alianza Editorial.

Mc LAUGHLIN, M. M., 1982. Supervivientes y substitutos: hyjos y padres del siglo IX al siglo XIII. In: Historia de la Infancia (L. De Mause, org.), pp. 121-205, Madrid: Alianza Editorial.

MELLO JORGE, M. H., 1979. Mortalidade por Causas Violentas no Município de São Paulo. Tese de Doutorado, São Paulo: Faculdade de Saúde Pública, Universidade de São Paulo. , 1988. Investigação Sobre a Morta-

lidade por Acidentes e Violências na Infância. Tese de Livre-Docência, São Paulo: Faculdade de Saúde Pública, Universidade de São Paulo.

MERCY, J. A.; ROSENBERG, M. L.; POWEL, K. E.; BROOME, C. V. \& ROPER, W. L., 1993. Public health policy for preventing violence. Health Affairs, 12: 07-29.

MNMMR (Movimento Nacional de Meninos e Meninas de Rua), 1991. Perfil do Menino de Rua: Propostas Alternativas. V Conferência Brasileira de Educação. Brasília, DF: MNMMR. (Mimeo.)

RESTREPO, L. C., 1993. El Saber de la Ternura. Violencia Intrafamiliar. Medellín: Litoarte.

SAFFIOTI, H., 1989. Exploração sexual de crianças. In: Crianças Vitimizadas. A Sindrome do Pequeno Poder (M. A. Azevedo \& V. N. A. Guerra, orgs.), pp. 49-95, São Paulo: Iglu. 
SANTOS, H. O., 1988. Crianças Acidentadas. São Paulo: Papirus.

SOUZA, E. R., 1992. Violência Velada e Revelada. Estudo Epidemiológico da Mortalidade por Causas Externas em Duque de Caxias - Rio de Faneiro. Tese de Mestrado, Rio de Janeiro: Escola Nacional de Saúde Pública, Fundação Oswaldo Cruz.

, 1994. Impacto da Violência Social na Saúde Pública do Brasil: Década de 80. São Paulo: Hucitec.

VEYNE, P., 1992. O império romano. In: História da Vida Privada (P. Arias \& G. Duby, orgs.), vol. 1, pp. 19-224, São Paulo: Companhia das Letras.
YUNES, J., 1993. Mortalidad por causas violentas en la región de las Américas. Boletin de la Oficina Sanitaria Panamericana, 114: 302-316.

YUNES, J. \& RAJS, D., 1994. Tendencia de la Mortalidad por Causas Violentas en la Poblacion General y entre los Adolescentes y Jovenes de la Region de las Américas. Washington, D.C.: Opas. (Mimeo.) 